\title{
Correction to: Decision Authority on Positive Mental Health in the Workforce: A Moderated Mediation Model of Social Support, Gender, Income, and Occupation
}

\author{
Tingting Gao ${ }^{1,2,3,4} \cdot$ Songli Mei ${ }^{1} \cdot{\text { Muzi } \mathrm{Li}^{2,3} \cdot \text { Carl D'Arcy }}^{5,6} \cdot$ Xiangfei Meng ${ }^{2,3}$ (i)
}

Published online: 10 June 2021

(c) Springer Nature B.V. 2021

\section{Correction to: Journal of Happiness Studies https://doi.org/10.1007/s10902-021-00384-3}

In the original publication, the affiliation of authors was published incorrectly. The correct version is given in this correction.

Publisher's Note Springer Nature remains neutral with regard to jurisdictional claims in published maps and institutional affiliations.

The original article can be found online at https://doi.org/10.1007/s10902-021-00384-3.

Xiangfei Meng

xiangfei.meng@mcgill.ca

1 School of Public Health, Jilin University, Changchun, Jilin, China

2 Department of Psychiatry, Faculty of Medicine and Health Sciences, McGill University, Montreal, QC, Canada

3 Douglas Research Centre, Montreal, QC, Canada

4 Centre for Health Management and Policy Research, School of Public Health, Cheeloo College of Medicine, Shandong University, Jinan, Shandong, China

5 School of Public Health, University of Saskatchewan, Saskatoon, SK, Canada

6 Department of Psychiatry, College of Medicine, University of Saskatchewan, Saskatoon, SK, Canada 